\title{
Three-Dimensional Structure of Golgi Complex in Rat Intestinal Epithelium and Its Morphological Changes during Fat Absorption
}

\author{
Toru Miyamoto and Keiichi TanakA \\ Department of Anatomy (Prof. K. TAnAKa) Tottori University School of Medicine, Yonago, Japan
}

Received November 13, 1981

Summary. The three-dimensional structure of the Golgi complex in rat intestinal epithelium and its morphological alteration during fat absorption were studied by the OsmiumDMSO-Osmium method.

1. The Golgi complex consisted of a Golgi stack which was a parallel array of flattened cisternae, numerous small vesicles of similar size, condensing vacuoles which expanded from the periphery of the cisterna, and the plexus of anastomotic tubules associated with many granules of various sizes.

2. During fat absorption, the condensing vacuoles of the Golgi complex were dilated and many lipid droplets appeared within the lumen of the condensing vacuoles, while the length and number of the parallel arrayed cisternae decreased remarkably. At 60 min after fat administration the membrane alteration reached its maximum. The Golgi complex consisted of only vacuoles containing lipid droplets at this time.

3. The lipid droplets in the vacuoles were manifested with a colored scanning electron micrograph which was prepared by superimposition of the secondary electron image and the backscattered electron image from a given view field of the specimen, projected in two different colors.

Since the discovery by Camillo Golgi of the Golgi complex in cells of nervous system, its structure has been studied in detail with light and transmission electron microscopes (DALTON and Felix, 1954). The functions of Golgi complex have also been investigated by histochemical and biochemical methods: elaboration of secretory granules, synthesis of polysaccharide components and formation of lysosomes are counted as its functions. As regards the Golgi complex in cells of the intestinal tract, transmission electron microscopic studies have established that it plays an important role in the absorption process of fat (CARDEll et al., 1967; Friedman and CARDELL, 1972, 1977).

During the last ten years, the scanning electron microscope (SEM) has been widely employed in the studies of the surface structures in cells and tissues, because it provides vivid three-dimensional images. Recently a specimen preparation technique called Osmium-DMSO-Osmium method (O-D-O method) was devised for the scanning electron microscope visualization of the intracellular structures (TANAKA and NAGURo, 1981). This method intends to remove the excess cytoplasmic matrices, which hide cell organellae, from the cracked surfaces by the maceration process with a dilute 
osmic solution. By the use of this method the three-dimensional structures of some cell elements were observed in detail (TAnaKa, 1980a; Masunaga, 1981; TAnaka and Kinose, 1981; Yamagata, 1982).

In the present study, the fine structure of the Golgi complex of the rat small intestine and its morphological changes during fat absorption are investigated by the $\mathrm{O}-\mathrm{D}-\mathrm{O}$ method. This paper also demonstrates the lipid droplets in the Golgi complex with a colored scanning electron micrograph which is produced by the superimposition method devised by TANAKa (1980b).

\section{MATERIALS AND METHODS}

The rat small intestine was used as the material. For the purpose of observing the alteration of the Golgi complex during fat absorption, a group of rats was starved for $48 \mathrm{hrs}$ with free water intake, then a gastric tube was inserted into the esophagus under ether anesthesia at scheduled times, and $1.5 \mathrm{ml}$ of corn oil was given through the tube. Tissue specimens were collected in the following manner from each rat at 10, 20, 30, 45 and $60 \mathrm{~min}$ after fat administration: the rat was laparotomized under ether anesthesia, and a portion of the intestinal tract, about $10 \mathrm{~cm}$ anal to the pylorus was resected.

The tissue was cut into small pieces, about $1 \times 1 \times 5 \mathrm{~mm}$ in size and treated by the O-D-O method: 1) The specimens were fixed at $4^{\circ} \mathrm{C}$ for $2 \mathrm{hrs}$ in $1 \%$ osmium tetroxide solution buffered at $\mathrm{pH} 7.4$ with $\mathrm{M} / 15$ phosphate buffer solution. 2) After rinsing the specimens were successively immersed in 25 and $50 \%$ dimethyl sulfoxide (DMSO) for 30 min each. 3) The specimens were frozen on to metal plate chilled with liquid nitrogen and cracked into two by a razor blade and a hammer (cracking apparatus: TF-1, EIKO Engineering Co.). 4) The cracked pieces were immediately placed in $50 \%$ DMSO for thawing. 5) After rinsing they were transferred into $0.1 \%$ osmium tetroxide solution buffered at $\mathrm{pH} 7.4$ with $\mathrm{M} / 15$ phosphate buffer solution and left standing at $4^{\circ} \mathrm{C}$ for $70 \mathrm{hrs}$. 6) The specimens were post-fixed for $1 \mathrm{hr}$ in $1 \%$ osmic solution and then treated by Murakami's conductive staining method (MuraKAMI, 1973). 7) The specimens were dehydrated with ethanol and dried in a critical point dryer (Hitachi HCP-2) with dry ice (TANAKA and Ino, 1974). 8) The dried specimens were coated with platinum in a ion-coater with a rotating stage (VX-10R, EIKO Engineering Co.) and observed with a field emission SEM (Hitachi HFS-2ST).

The colored scanning electron micrograph was prepared by TANAKA's method (TANAKA, 1980b). 1) After DMSO cracking and dehydration with ethanol, some specimens were stained with lead by KushidA's method (Kushida, 1966). 2) They were dried by the critical point drying method and then very thinly coated with platinum. 3) The specimens were observed in the field emission SEM equipped with a highly sensitive backscattered electron detector; and secondary electron (SE) and backscattered electron (BSE) images were successively taken under the same conditions of the microscope. 4) Pictures of SE and BSE images on developed negative films were mounted separately between two glass cover slips. 5) The pictures were superimposed on a screen using two projectors of the same type but with different color filters (In this study, yellow and red filters were used.) The resulting pictures were photographed with a color film. Colored scanning electron micrographs with the SE and the BSE information were thus obtained. 


\section{RESULTS}

\section{A. The Golgi complex of intestinal epithelium in normal rats}

This organella usually was located at the juxtanuclear portion (Fig. 1). It consisted of a Golgi stack, which was a parallel array of flatted cisternae, numerous small vesicles of about $100 \mathrm{~nm}$ diameter and condensing vacuoles which expanded from the periphery of the cisternae (Fig. 2).

On the inner concave face of the Golgi stack was a plexus constructed of anastomotic tubules. In the plexus, there were many granules of various sizes which were attached to the tubules at a portion. These granules were probably growing lysosomes.

In the Golgi stack, the outermost cisterna showed a net-like structure, being riddled with many small holes (Fig. 3). The cisterna in the middle part of the stack appeared as a plate-like structure without any holes. The two cisternae on the inner concave face had a central plate and peripheral tubules (Fig. 4). As these tubules anastomosed each other, the lumina of the two central plates seemed to be in communication indirectly via the tubules.

\section{B. Golgi complex of intestinal epithelium from rats starved for $48 \mathrm{hrs}$}

There were no remarkable changes in the Golgi complex as compared with that of the normal rat. It was only characteristic in the Golgi complex that the condensing vacuoles expanding from the periphery of the cisternae were completely empty in their interiors (Fig. 5).

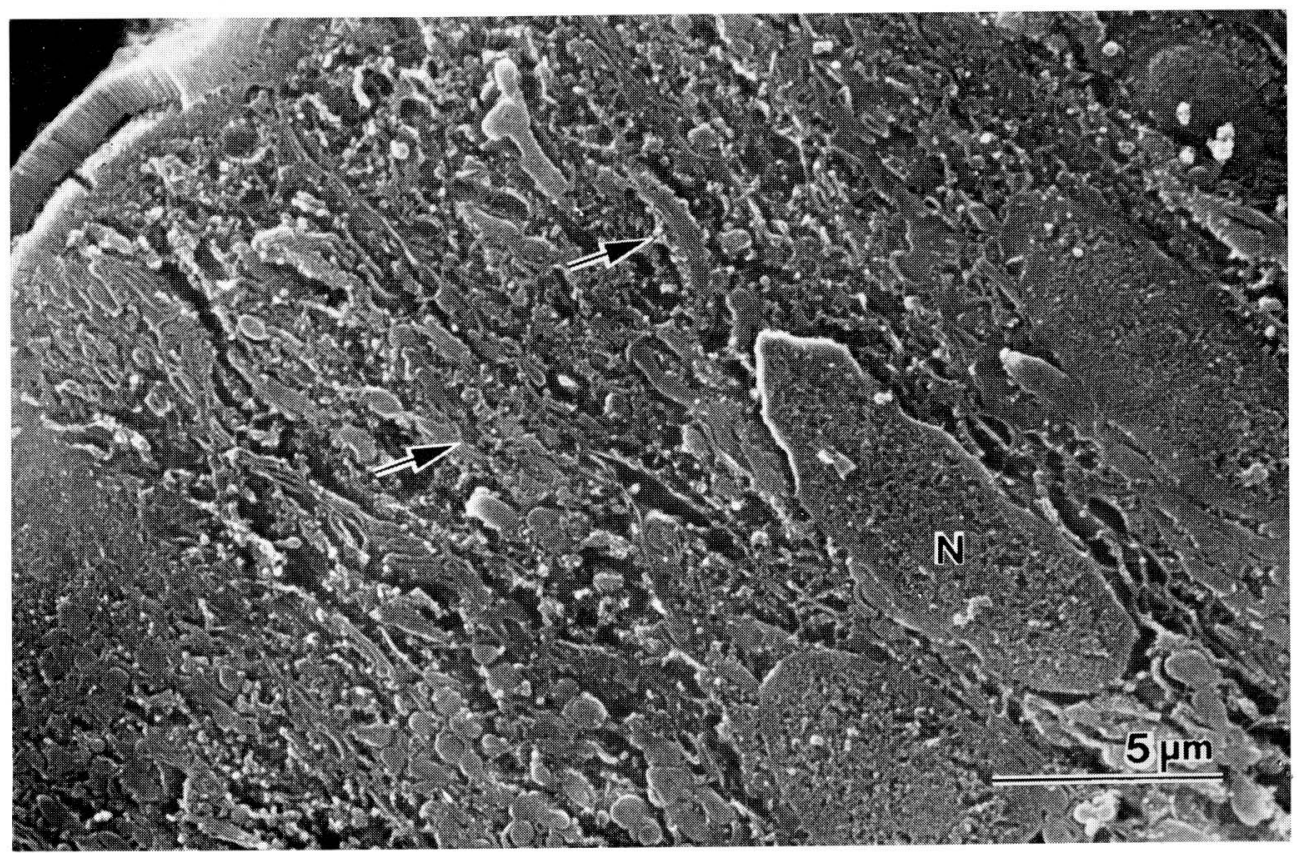

Fig. 1. Cracked surface of intestinal epithelium in a normal rat. Golgi complexes (arrows) are located on the apical side of the nuclei $(N)$. 


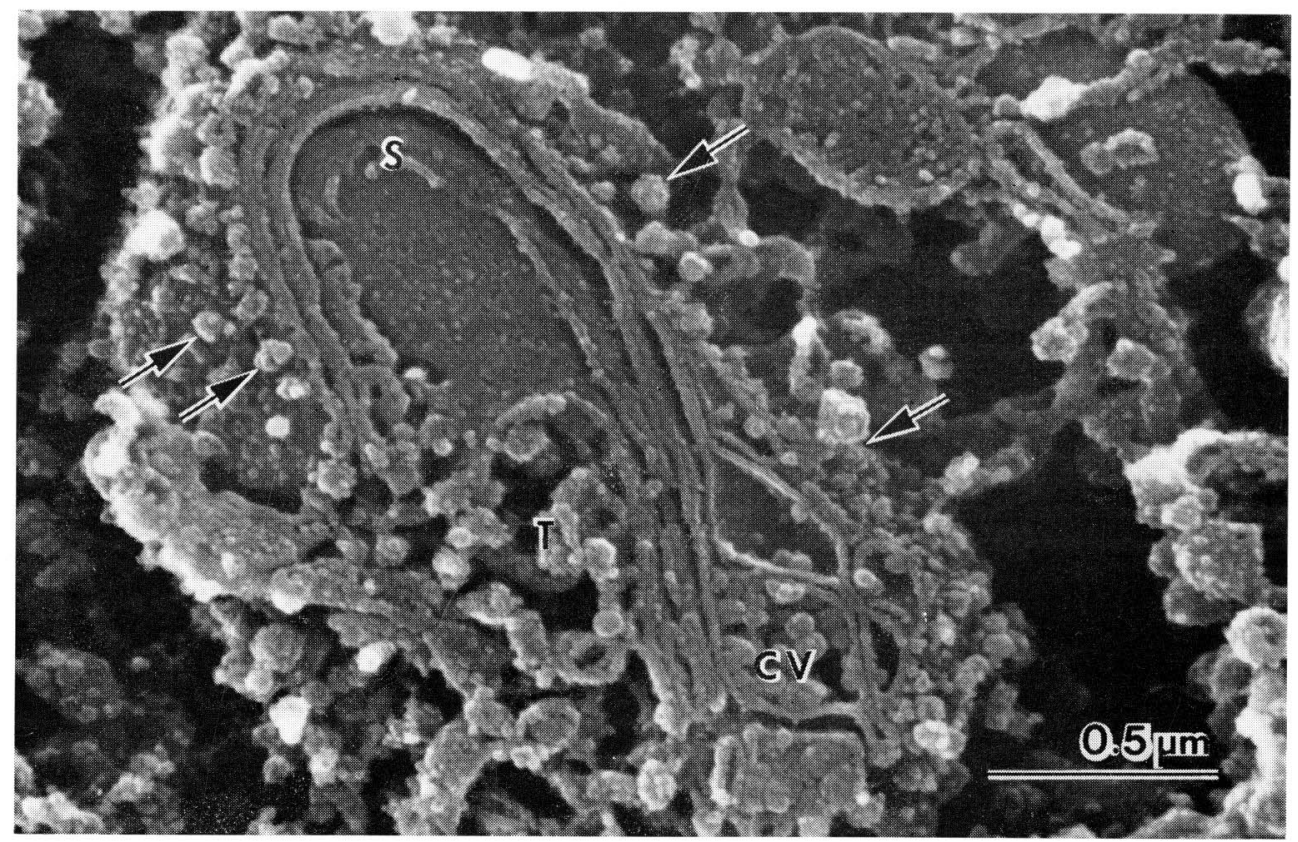

Fig 2. Golgi complex in the epithelium of the small intestine from a normal rat. $S$ stack of cisternae, $T$ plexus of anastomotic tubules, $C V$ condensing vacuole. Arrows show vesicles.

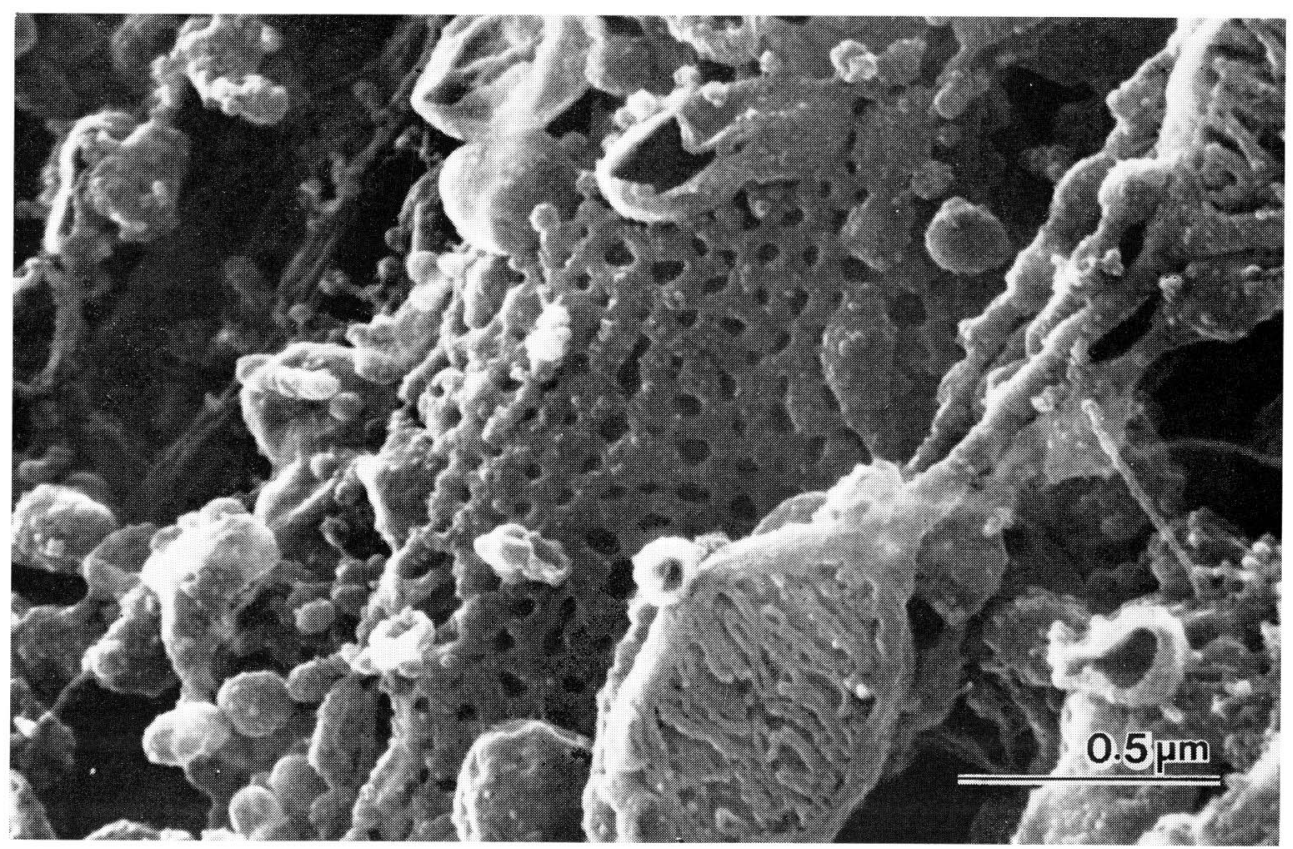

Fig. 3. Outermost cisterna of a Golgi stack from a control rat, showing a net-like structure. 




Fig. 4. Golgi stack in the intestinal epithelium of a normal rat. Two cisternae on the left side of the stack have a central plate-like portion $(*)$ and peripheral tubules (arrows). 


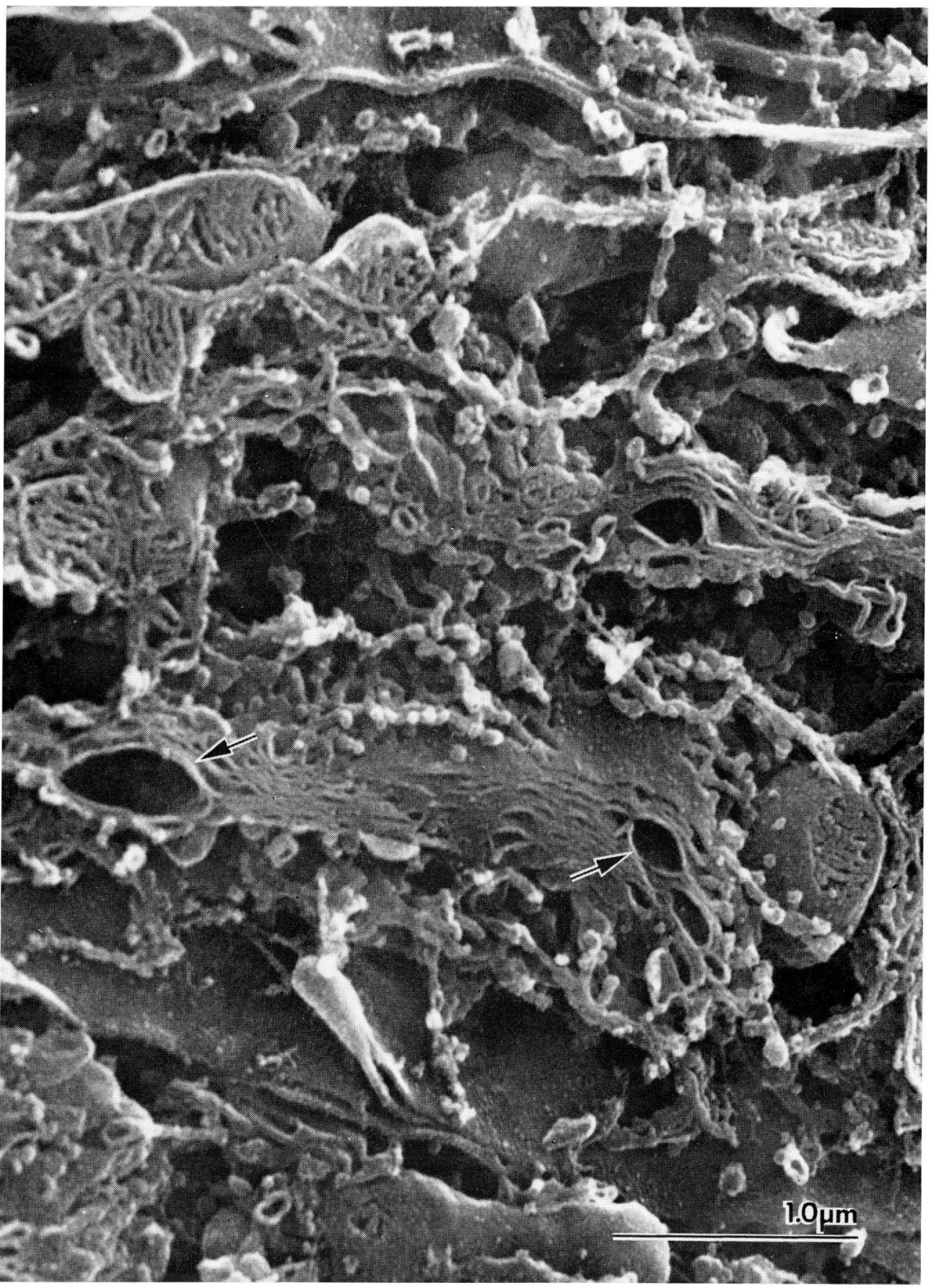

Fig. 5. Golgi complex of a $48 \mathrm{hr}$ starved rat. The interior of the condensing vacuoles (arrows) is empty. 


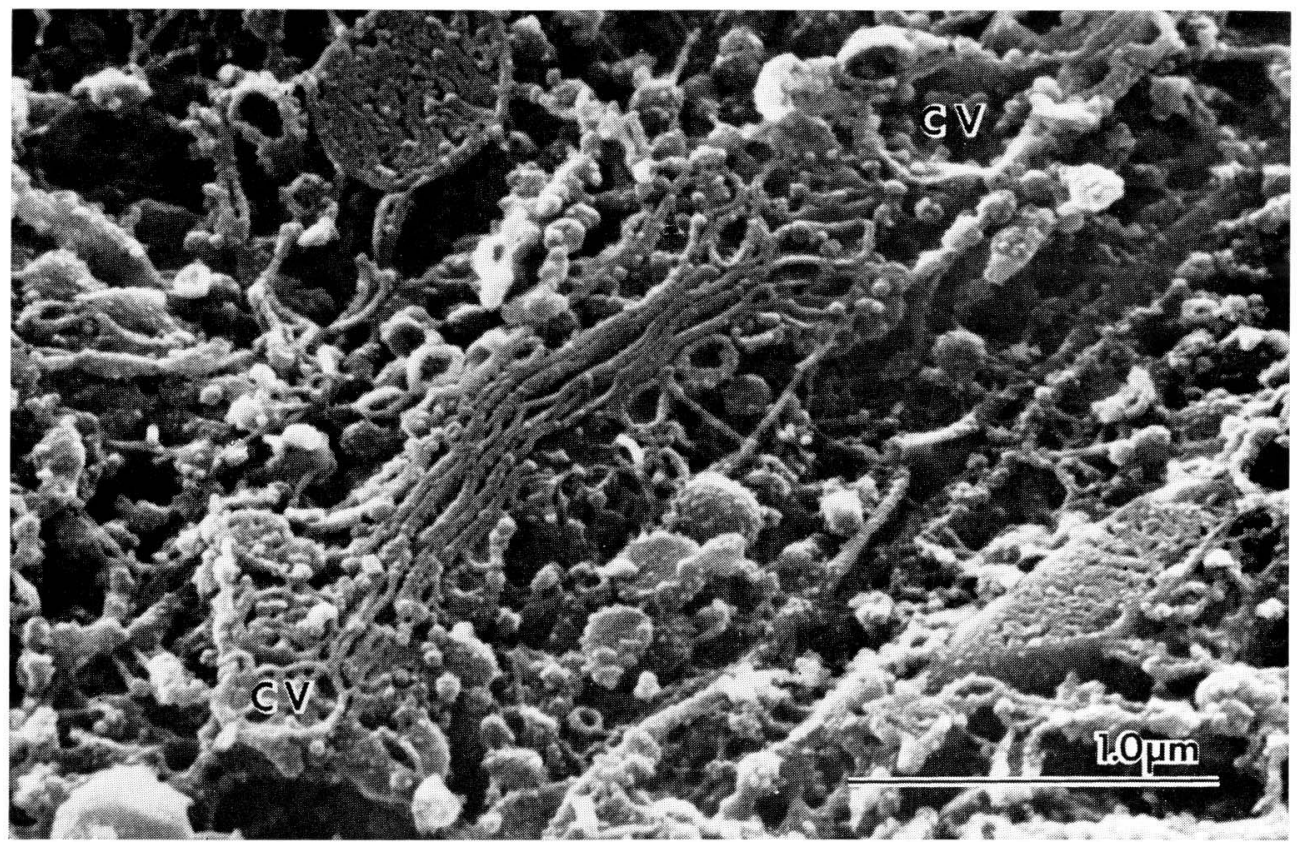

Fig. 6. Golgi complex at $10 \mathrm{~min}$ after fat administration. Lipid droplets appear in the lumen of condensing vacuoles $(C V)$.



Fig. 7. Lipid droplets (arrows) pouring into a condensing vacuole from vesicles, from a rat $10 \mathrm{~min}$ after fat administration. 


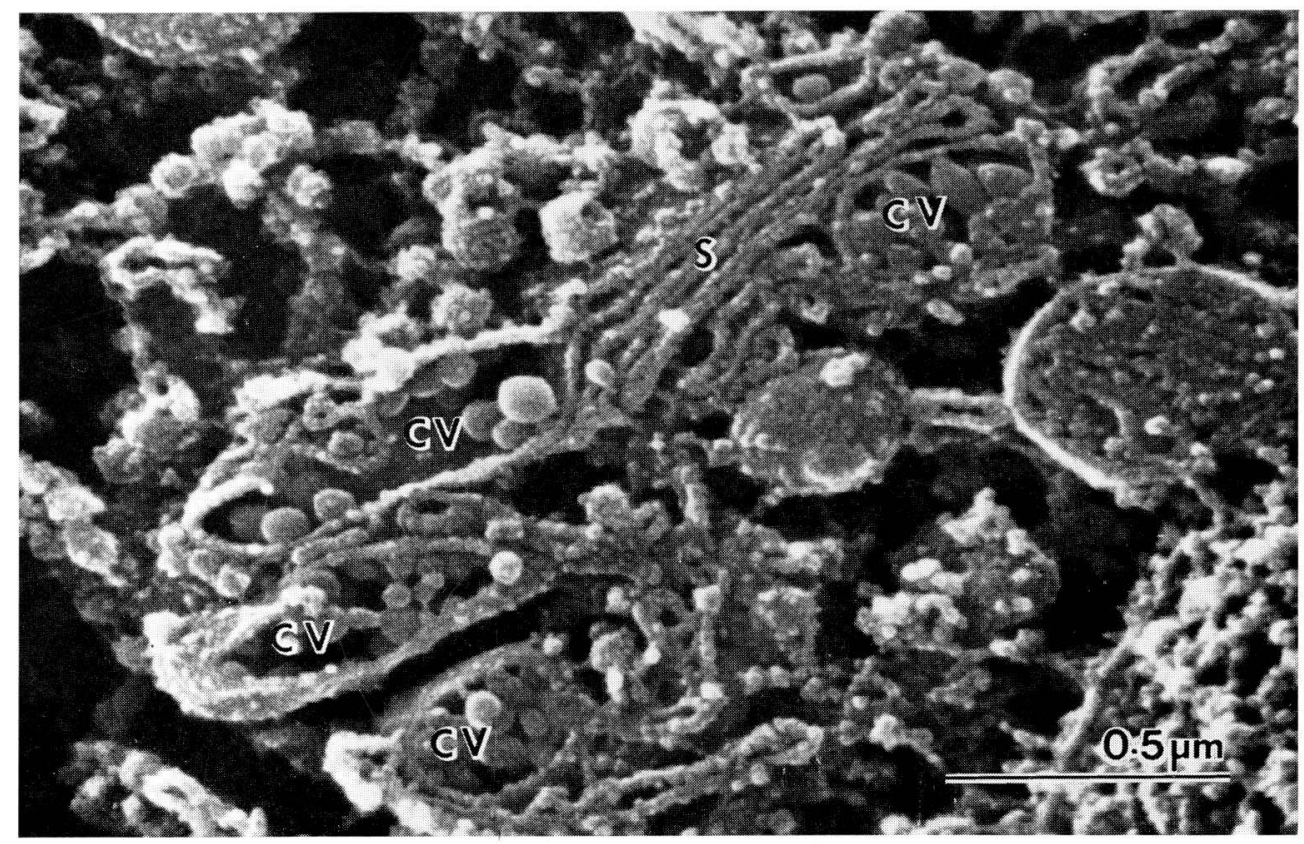

Fig. 8. Golgi complex at $20 \mathrm{~min}$ after fat administration. The condensing vacuoles $(C V)$ containing lipid droplets are dilated markedly and the stack $(S)$ is shortened.



Fig. 9. Golgi complex at $30 \mathrm{~min}$ after fat administration. The stack $(S)$ is further decreased in size. 




Fig. 10. Golgi complex at $45 \mathrm{~min}$ after fat administration. Note enlarged condensing vacuoles $(C V)$ containing numerous lipid droplets. $S$ stacks of cisternae. 


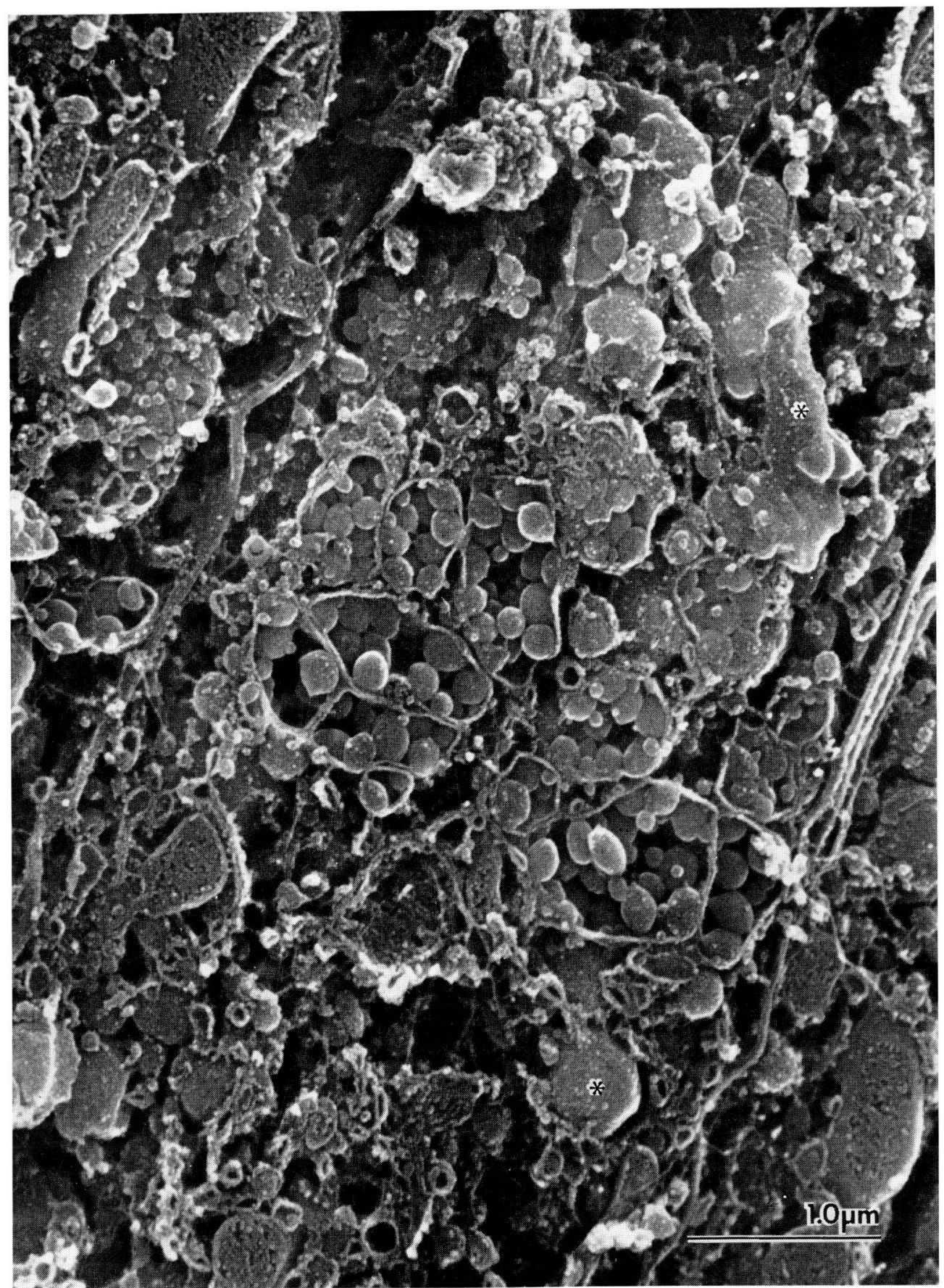

Fig. 11. Golgi complex at $60 \mathrm{~min}$ after fat administration. It consists exclusively of vacuoles which contain lipid droplets. Asterisks indicate enlarged, lipid containing vacuoles seen from the membrane outside. 


\section{Alteration of Golgi complex during fat absorption}

10 min after fat administration

The constitution of the Golgi complex was not yet changed, but several granules (lipid droplets) appeared in the condensing vacuoles at the periphery of the cisternae (Fig. 6). These lipid droplets seemed to be transferred from the cell surface to the Golgi complex via the vesicles attached to the surface of the stack, as we could frequently observe that the contents of the vesicles poured themselves into the lumina of the condensing vacuoles (Fig. 7).

\section{0 min after fat administration}

In the Golgi stack, the condensing vacuoles dilated markedly, while the parallel arrayed cisternae became smaller in size. The granules in the condensing vacuoles grew larger and increased in number (Fig. 8).

\section{0 and 45 min after fat administration}

The cendensing vacuoles increased remarkably in size and number, and the stack became smaller (Fig. 9, 10).

\section{0 min after fat administration}

At this time the Golgi complex was constructed of only vacuoles, which contained many lipid droplets (Fig. 11). The parallel arrayed cisternae could not be observed anywhere.

When such specimens are observed in BSE mode of the SEM after being stained with lead by KusHiDA's method, the granules in the vacuoles appear bright in the dark



Fig 12. Schematic drawing of morphological changes in Golgi complex during fat absorption. A Golgi complex of $48 \mathrm{hr}$ starved rat, $B 20$ min after fat administration, $C 45 \mathrm{~min}$ after fat administration, $D 60 \mathrm{~min}$ after fat administration. 


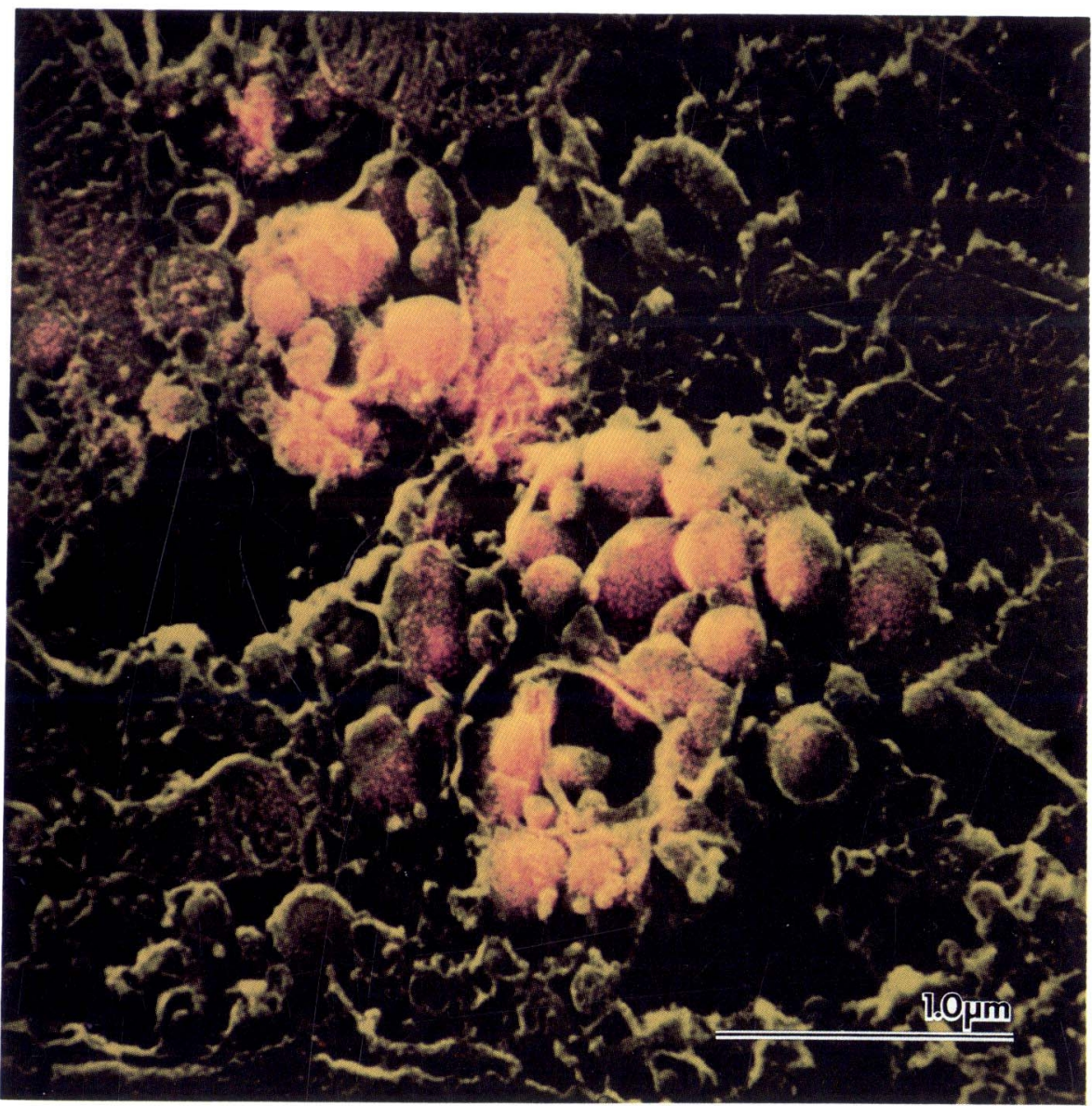

Fig. 13. Colored scanning electron micrograph of the Golgi complex at $60 \mathrm{~min}$ after fat administration. Lipid droplets in the vacuoles visualized by backscattered electron image are shown in orange, while surface information by secondary emission is demonstrated in green.

view field, as lipid has been heavily impregnated with lead. By superimposing this BSE image with the SE image of the same view field, a colored scanning electron micrograph is synthesized by TANAKA's method (Fig. 13). The colored micrographs prove suited to identify lipid droplets in the vacuoles, as they simultaneously give us the surface information based on the SE image and the information of atomic number contrast depending on the BSE image.

\section{DISCUSSION}

It has been well known by many light microscopic studies that the Golgi complex changes its form variously in accordance with the functional phases of the cell. With the development of transmission electron microscopes, the fine structure and its morphological changes depending on various functional phases have been investigated in 
detail. Until recently scanning electron microscopy has not been applied to the studies of this category, because there has been no good method to expose the Golgi complex in its three-dimensional, intracellular position, though the SEM itself is very suitable for studying a complicated structure like this organella.

Fortunately the O-D-O method recently devised by TANAKa and NAGURo (1981) has proven capable of disclosing various inner-cell structures. In the present study this method was applied successfully in studying the construction of the Golgi complex and its morphological alterations during fat absorption.

The three-dimensional structure of Golgi complex was reported by TANAKA and Kinose (1981) in cells of rat epididymis. According to their SEM findings, the Golgi complex of epididymal cells consisted of a Golgi stack attached with numerous small vesicles, a plexus of anastomotic tubules associated with granules of various sizes, ranging from 50 to $500 \mathrm{~nm}$, and vacuoles. The present findings showed that the Golgi complex of rat small intestine cells was almost the same in construction. However, the number of the flattened cisternae was smaller in the intestinal cells than in the epididymal cells and the outermost cisterna of the former was permeated with only one kind of holes of similar size, whereas both larger and smaller holes were observed on the outermost cisterna of the latter. In the intestinal epithlium, two or three cisternae on the inner concave face consisted of a central plate and peripheral tubules, but those of epididymal cells showed only a plate-like structure. The most conspicuous difference was that the Golgi stack of the intestinal epithelium always had condensing vacuoles at the periphery of the cisternae; in contrast, condensing vacuoles were hardly seen in the epididymal cell.

To summarize the construction of the Golgi complex was fundamentally the same in the two cell types, though certain differences were distinguishable.

The morphological changes of the Golgi complex in the intestinal epithelium during fat absorption were investigated by FrIEDMAN and CARDELL (1977) by transmission electron microscopy. Their results conform well with those of our SEM study, although the precise three-dimensional structure and its changes of the Golgi complex have been first visualized by the latter. According to their TEM findings, the condensing vacuoles were dilated and contained small droplets of lipid within their lumen, while the length and number of the parallel arrayed cisternae decreased gradually. At 60 min after fat administration, the alteration of the Golgi complex reached a maximum. Though FrIEDMAN and CARDELL observed the remnants of the Golgi stack still at this time, we could not observe any trace of the stack. Whether the Golgi stack disappears completely at the maximum time of membrane alteration or not remains to be studied.

The recovery process of the membrane alteration in the Golgi complex is also the subject for a future study.

\section{REFERENCES}

Cardell, R. R., C. Badenhausen and K. R. Porter: Intestinal triglyceride absorption in the rat. An electron microscopic study. J. Cell Biol. 34: 123-155 (1967).

Dalton, A. J. and M. D. Felix : Cytologic and cytochemical characteristics of the Golgi substance of epithelial cells of the epididymis in situ, in homogenates and after isolation. Amer. J. Anat. 94: 171-207 (1954). 
Friedman, H. I. and R. R. Cardell, Jr. : Effects of puromycin on the structure of rat intestinal epithelial cells during fat absorption. J. Cell Biol. 52: 15-40 (1972).

during fat absinal cells study. Anat. Rec. 188: 77-102 (1977).

Kushida, H.: Staining of thin section with lead acetate. J. Electron Microsc. 15: 93-94 (1966).

Masunaga, Y.: Scanning electron microscopic studies on mitochondria in zona fasciculata of adrenal cortex. (In Japanese) J. Yonago Med. Assoc. 32: 24-30 (1981).

Murakami, T.: A metal impregnation method of biological specimens for scanning electron microscopy. Arch. histol. jap. 35: 323-326 (1973).

Tanaka, K.: Scanning electron microscopy of intracellular structures. Int. Rev. Cytol. 68: 97-125 (1980a).

: A method for preparing colored scanning electron micrographs using SE and BSE images. Scanning 3: 206-210 (1980b).

Tanaka, K. and A. Iino: Critical point drying method using dry ice. Stain Technol. 49: 203-206 (1974).

Tanaka, K. and T. Kinose: Three-dimensional microanatomy of intracellular structures. Special reference to the Golgi complex. In: (ed. by) D. J. Allen et al.: Three-dimensional microanatomy of cells and surface tissues. Elsevier/North Holland, New York, 1981. (p. 21-32).

Tanaka, K. and T. Naguro: High resolution scanning electron microscopy of cell organelles by a new specimen preparation method. Biomed. Res. 2, Suppl.: 63-70 (1981).

Yamagata, K.: Scanning electron microscopic studies on hamster hepatic parenchymal cells. (In Japanese) J. Yonago Med. Assoc. 33: 227-239 (1982).

宮本享

T683 鳥取県米子市西町 86

鳥取大学医学部

第二解剖学教室
Dr. Toru Mry амото

Department of Anatomy

Tottori University School of Medicine

Yonago, 683 Japan 